\title{
RASTREAMENTO DOS PROGRAMAS DE SAÚDE VOLTADOS PARAACRIANCA ELABORADOS PELAS TRÊS ESFERAS DE GOVERNO
}

\author{
Tracking of health programs for children developed by three government levels
}

\author{
Danize Aparecida Rizzetti ${ }^{1}$ e Claudia Morais Trevisan ${ }^{2}$
}

\begin{abstract}
| RESUMO
As políticas públicas de saúde constituem-se como resposta do Estado às necessidades da população. Aquelas voltadas para criança promovem tanto o seu desenvolvimento integral, como também o da sociedade. Os objetivos do estudo foram verificar os programas de saúde voltados para a criança elaborados a nível Federal, Estadual e Municipal; identificar quais estão implantados no Município e os que atuam nas escolas. A pesquisa foi descritiva exploratória, cujos dados foram coletados através de entrevista semi-estruturada aplicada aos responsáveis pela área infantil das Secretarias Municipal de Educação e de Saúde de Santa Maria entre os meses de junho a agosto de 2006. Foram encontrados 30 programas, sendo 13 a nível Federal, 10 a nível Estadual e sete a nível Municipal. No município estão implantados 25 programas, oito deles atuando nas escolas. Conclui-se que ainda existem poucas políticas públicas de saúde destinadas à criança, principalmente as que visam atuação no ambiente educacional.
\end{abstract}

Palavras-chaves: Políticas de saúde, criança, níveis Federal, Estadual e Municipal.

\section{SUMMARY}

Public health politics are established as the State's response to attend the population needs. Those politics turned to children may promote their integral development as well as the societies. The aims of the study were to verify the health programs turned to children being elaborated in Federal, State and Municipal government levels; identify which are introduced in the Municipal District and the ones which act in the schools. This was a descriptive exploratory research in which information was collected through semi-structured interview applied to people responsible for the infantile area of the Health and Education Municipal Secretariat of Santa Maria between the months of June and August 2006. Thirty programs were found, thirteen being from Federal level; ten from State level and seven from Municipal level. Twenty-five programs are implemented in the Municipal District, eight of them acting in schools. It is concluded that still there aren't enough health public politics designated to children, particularly the ones that should act within the educational environment.

Key-words: Health politics, children, Federal, State and Municipal levels.

\section{INTRODUÇÃO}

As políticas públicas constituem-se como resposta do Estado, em todos os seus níveis de governo, às necessidades da população em seu território específico. As políticas públicas em geral, mais especificamente as de saúde, efetivamente implementadas em cada época refletem o momento histórico em que foram formuladas, as condições econômicas vigentes, os avanços do conhecimento científico, bem como a capacidade dos cidadãos, grupos e classes sociais se organizarem e influenciarem as definições políticas formais e informais ${ }^{1}$.

Em se tratando de políticas públicas para atender às necessidades das crianças, a promulgação do Estatuto da Criança e do Adolescente (1990) e da Lei de Diretrizes e Bases da Educação Nacional (1996), expressaram condições favoráveis para a criação de programas públicos visando à saúde e à educação da população infantil2. De fato isso foi um grande benefício, já que estas crianças vão estar em algum momento no comando do país. Dessa forma, programas voltados a este público devem ser prioridades nacionais, pois um país que cuida de suas crianças viabiliza o seu futuro ${ }^{3}$.

As políticas que visam à educação e à saúde infantil servem como um meio de promover, não apenas o desenvolvimento integral da criança, como também de toda a

Trabalho realizado no Departamento de Fisioterapia e Reabilitação da Universidade Federal de Santa Maria (UFSM)/RS.

${ }^{1}$ Acadêmica do curso de Fisioterapia da UFSM

${ }^{2}$ Professora Doutora do Departamento de Fisioterapia e Reabilitação do curso de Fisioterapia da UFSM 
sociedade $^{2}$. Diante disso, verificar a implantação de políticas públicas voltadas para a criança elaboradas pelas três esferas de governo faz-se necessário para podermos analisar se o Estado dá a devida assistência, garantida por lei, às crianças, principalmente àquelas que freqüentam o ambiente educacional nas escolas de Santa Maria, Rio Grande do Sul, local em que residimos.

Dessa forma, os objetivos propostos pelo presente estudo foram verificar os programas de saúde voltados para a criança elaborados a nível Federal, Estadual e Municipal; identificar quais estão implantados no Município de Santa Maria e destes, os que atuam no ambiente escolar e analisar a importância destes programas para a promoção de saúde no ambiente escolar.

\section{MATERIAIS E MÉTODOS}

Esta pesquisa caracterizou-se como descritiva do tipo exploratória, na qual os fatos foram observados, registrados, analisados, classificados e interpretados, sem a interferência das pesquisadoras. A amostra foi constituída pelos responsáveis pela área infantil das Secretarias Municipal de Saúde e de Educação do município de Santa Maria, Rio Grande do Sul, além da Coordenadoria Regional de Saúde, estabelecida na mesma localidade. Foram incluídos no estudo aqueles sujeitos responsáveis pela área infantil nas instituições consultadas e que aceitaram fazer parte da amostra, assinando, após o esclarecimento detalhado da pesquisa, o Termo de Consentimento Livre e Esclarecido (TCLE) e o Termo de Confidencialidade (TC), conforme exigência do Ministério da Saúde de acordo com a Resolução 196/96.

Os dados foram coletados entre os meses de junho a agosto de 2006, através de visita previamente agendada às instituições participantes. Após a concordância em participar do estudo e da assinatura do TCLE e do TC, os participantes responderam a um questionário semi-estruturado com perguntas abertas, criado e aplicado pelas pesquisadoras, cuja finalidade foi a de investigar as principais políticas públicas de saúde voltadas para a criança elaboradas pelas três esferas de Governo.

As variáveis em estudo no presente trabalho foram as políticas públicas de saúde voltadas para a criança elaboradas a nível Federal, Estadual e Municipal e as políticas implantadas no ambiente escolar. Por se tratar de um estudo descritivo, os dados foram analisados pela estatística descritiva.

\section{RESULTADOS E DISCUSSÃO}

Foram encontradas 30 políticas públicas de saúde voltadas para a criança elaboradas pelas três esferas de Governo. Treze delas foram implantadas a nível Federal, que serão detalhadas a seguir:

- Programa Veja Bem Brasil

É um programa promovido pelo Conselho Brasileiro de
Oftalmologia em parceria com o Ministério da Educação, no qual se destaca o papel do professor na identificação precoce dos problemas visuais, através de testes realizados na própria escola, e na busca de soluções adequadas, o que contribui para maior envolvimento da comunidade nas ações em benefício da saúde escolar em geral.

- Programa Nacional de Imunizações (PNI)

O Ministério da Saúde oferece, para todas as crianças, vacinas contra diversas doenças, incluindo tétano, coqueluche, difteria, sarampo, caxumba e as formas graves de tuberculose. As crianças recebem também vacinas contra a meningite e contra a hepatite B.

- Hospital Amigo da Criança

Esse programa visa à promoção, proteção e apoio à amamentação, por meio da melhoria de práticas e rotinas em maternidades. Nessas unidades os profissionais de saúde oferecem atendimento mais humanizado à mãe e ao recémnascido.

- Programa Carteiro Amigo

Esse programa capacita, com apoio do ministério, secretarias estaduais e municipais de saúde, carteiros que passam informações e entregam materiais educativos sobre amamentação para as famílias, beneficiando muitas crianças menores de um ano de idade e gestantes.

\section{- Assistência ao Recém-Nascido}

Visa contribuir para a redução das taxas de mortalidade neonatal, principal causa de óbito no primeiro ano de vida. Com o objetivo de melhorar a qualidade da atenção perinatal, o Ministério da Saúde vem investindo na melhoria da qualidade e aumento da cobertura do pré-natal, humanização do parto e nascimento, redução das taxas de cesarianas e criação dos Centros de Parto Normal.

- Programa Nacional de Triagem Neonatal

Visa à identificação por meio do "teste do pezinho", de bebês portadores de doenças congênitas, para tratá-los precocemente e acompanhar o desenvolvimento da criança.

- Programa Fome Zero

Através desse programa, é proporcionada aos CMEI a distribuição de hortifrutigranjeiros e leite. No município de Santa Maria, a distribuição de leite é feita pela UNI, uma produtora de laticínios da Universidade Federal de Santa Maria através de um convênio com a CooProl, e a distribuição dos hortifrutigranjeiros é feita pela cooperativa CooEsperança.

\section{- Caderneta da Criança}

A Caderneta da Criança traz dados sobre as condições de saúde do recém-nascido, a gravidez, o parto e o puerpério, além de trazer orientações importantes sobre uma alimentação saudável, sobre o crescimento infantil e sobre o calendário básico de vacinação. A Caderneta de Saúde da Criança acompanha as crianças até os dez anos de idade.

- Programa de Incentivo ao Aleitamento Materno

O programa visa incentivar o aleitamento materno como 
alimento exclusivo até os seis meses de idade do bebê e intercalado com outros alimentos até os dois anos de vida da criança. Através de folders informativos, distribuídos gratuitamente em todas as Unidades Básicas de Saúde e Hospitais, as pessoas podem conhecer os benefícios da amamentação para o bebê e para a mãe.

\section{- Rede Nacional de Bancos de Leite Humano}

É a maior rede do mundo e tem sido reconhecida internacionalmente pela sua qualidade. Esta rede tem a missão de promover a saúde de bebês, especialmente os que nascem prematuros e de baixo-peso. É responsável também, pela disseminação de informações educativas para milhares de gestantes. Cerca de 100 mil litros de leite humano são coletados por estes Bancos.

\section{- Programa de Combate à Diarréia}

Este programa tem como objetivos informar à população, através de folders informativos, as causas da diarréia e os procedimentos que devem ser feitos quando a criança apresenta os sintomas. Através desse programa, o Ministério da Saúde fornece para as Unidades Básicas de Saúde a vacina contra o Rota Vírus, que é um dos principais agentes causadores da diarréia, essa vacina faz parte do esquema de vacina do bebê.

- Norma Brasileira de Comercialização de Alimentos para Lactentes e Crianças de Primeira Infância e de Bicos, Chupetas e Mamadeiras - NBCAL (Lei n ${ }^{\circ} 11265$ )

Foi publicada no dia 04 de janeiro de 2006, regulamentando a comercialização de alimentos para lactentes e crianças de primeira infância e também de produtos de puericultura correlatos.

\section{- Método Mãe-Canguru}

Visa à humanização do atendimento ao bebê prematuro e de baixo peso, melhorando o vínculo entre a mãe e o filho, diminuindo o tempo de separação, estimulando a prática da amamentação, diminuindo a infecção hospitalar, e a permanência do bebê no hospital.

A nível Estadual, foram elaboradas 10 políticas de saúde para o público infantil, sendo elas:

- Atendimento às Dificuldades Auditivas

Através da parceria entre a Sociedade de Otologia e os Ministérios da Educação e Saúde, foi criado um vídeo-teste no qual a professora aplica o teste auditivo nas crianças, na própria escola, com posterior encaminhamento daquelas que apresentam anormalidades auditivas para profissionais especializados.

\section{- Atenção à Saúde Ocular}

Política de fundamental importância e inclui as atividades de promoção, prevenção e recuperação da função visual. Nesse programa, o professor, capacitado pelas secretarias de Educação e Saúde, realiza na própria escola a avaliação inicial as crianças da Educação Infantil, Primeira Série do Ensino Fundamental e todas as demais, que apresentem sinais e sintomas de prejuízos na acuidade visual.

- Controle da Qualidade da Água Consumida nas Escolas Estaduais, Creches e Aldeias Indígenas

Assegura à população escolar e indígena o fornecimento de água em condições de potabilidade, reduzindo a zero a ocorrência de patologias de veiculação hídrica. Dessa forma, visa à melhoria da saúde e das condições de vida da comunidade; a diminuição da mortalidade em geral, principalmente da infantil; e a diminuição da incidência de doenças relacionadas com a água.

- Controle Toxicológico dos Alimentos Consumidos em Escolas Estaduais, Creches e Aldeias Indígenas

Nesse programa, a Seção de Saúde da Criança e do Adolescente fornece informações e orientações no sentido de melhorar a qualidade dos alimentos consumidos pela população infantil. Apóia tecnicamente as nutricionistas, merendeiras e responsáveis pelo armazenamento e fornecimento de merenda escolar das escolas estaduais.

- Política Estadual de Triagem Neonatal

A Política de Triagem Neonatal visa fazer o diagnóstico precoce das seguintes doenças: Fenilcetonúria, Hipotireoidismo Congênito, Doença Falciforme e outras hemoglobinopatias. Esta atividade é conhecida popularmente como "Teste do Pezinho".

\section{- Programa Viva a Criança}

É um programa prioritário do Governo do Estado em articulação com os municípios e com a colaboração de diversas entidades representativas da sociedade organizada com a finalidade de reduzir os índices de mortalidade infantil no Rio Grande do Sul.

- Notificação Compulsória de Maus Tratos contra Crianças e Adolescentes

O programa objetiva contribuir para a redução da violência contra a criança e o adolescente através de informações que permitam melhor conhecer a caracterização dos maus tratos e a formulação de políticas públicas efetivas. Além disso, pretende padronizar todas as notificações que o Conselho Tutelar recebe do Serviço de Atendimento em Saúde.

- Programa Primeira Infância Melhor

O programa é parte de uma ofensiva do governo gaúcho contra a mortalidade infantil. A proposta é formar equipes encarregadas de visitar famílias com filhos até seis anos de duas a três vezes por mês. Os agentes, contratados pelas prefeituras dos municípios participantes do programa, dão orientações aos pais.

- Política de Alimentação e Nutrição

Tem como objetivo principal criar ações voltadas para a prevenção primária, secundária e terciária de agravos, atuando através de sete linhas específicas: educacionais, vigilância epidemiológica, pesquisa, posicionamento conceitual sobre nutrientes ou alimentos específicos, incentivo a produção e distribuição, suplementação e fortificação, monitoramento de qualidade.

- Programa de Educação Alimentar

O programa apresenta como objetivo geral reduzir a incidência e a prevalência das doenças correlacionadas com o 
hábito alimentar em nosso meio e como objetivos específicos prevenir as conseqüências do hábito alimentar inadequado e estimular a manutenção do hábito alimentar saudável. A população alvo são as gestantes, os pré-escolares, os jovens em idade escolar e universitários.

Já a nível Municipal, encontraram-se sete políticas públicas de saúde destinadas à população infantil, as quais são descritas abaixo:

\section{- Projeto Escola e Saúde}

Desenvolvido em parceria com as Secretarias de Saúde, Educação, Assistência Social e Cidadania e Secretaria Geral de Governo, que tem como proposta, realizar exames de saúde na população estudantil e um estudo epidemiológico na área odontológica, com conseqüente atendimento, desencadeando o processo de integração entre Escola e Unidades de Saúde.

\section{- Serviço de Pós-Alta Hospitalar (SPAH)}

Através desse programa, os pacientes do Sistema Único de Saúde podem receber em casa o atendimento de médicos, psicólogos, fisioterapeutas, fonoaudiólogos e nutricionistas da Casa de Saúde. A implantação deste programa possibilita um maior número de leitos do SUS disponíveis no hospital.

\section{- Programa Acolhe Bebê}

O programa tem como objetivo reduzir a mortalidade infantil, através de captação precoce dos recém-nascidos do município, da identificação dos mesmos e do controle do seu crescimento, desenvolvimento e fatores de risco inerentes, garantindo o acesso, acolhimento e vínculo com a Unidade Básica de Saúde de referência.

- Programa Acolher

O programa visa fornecer apoio e cuidado a crianças vítimas de abuso e violência sexual e a suas famílias. É executado pela secretaria de Assistência Social e Cidadania, além de contar com atividades dos cursos de Serviço Social, Psicologia, Ciências Sociais e Enfermagem das universidades da cidade.

- Sistema de Vigilância Alimentar e Nutricional

Tem como objetivo monitorar as condições dos grupos desfavorecidos da população de risco, e proporcionar um método de avaliação rápida e permanente de todos os fatores que influenciam os padrões de consumo alimentar e o estado nutricional. Em Santa Maria, o SISVAN está vinculado ao Programa Bolsa Família, pelo fato de que as famílias que recebem esse benefício têm o dever de manter seus filhos na escola e dar-lhes uma boa qualidade nutricional. O primeiro dever é monitorado pela Secretaria de Educação, e o segundo pelo SISVAN.

\section{- Programa de Carências Nutricionais}

Através de meio impresso, são divulgadas informações sobre a higiene de alimentos, medidas caseiras para se promover a higienização, além de orientações sobre nutrição e sobre o perigo de ingerir alimentos contaminados.

\section{- Programa de Capacitação de Educadores}

É um programa no qual os profissionais da área da saúde orientam e capacitam professores para abordarem assuntos sobre sexualidade nas escolas, principalmente para os alunos adolescentes.

Nem todos os programas existentes nas três esferas de Governo são encontrados no município de Santa Maria. Dos 30 programas existentes em todo o país, foi verificada a existência de 25 deles neste município. Onze, das 13 políticas elaboradas a nível federal estão implantadas nessa localidade, são elas: Programa Veja Bem Brasil; Programa Nacional de Imunizações (PNI); Hospital Amigo da Criança; Programa Carteiro Amigo; Assistência ao Recém-Nascido; Programa Nacional de Triagem Neonatal; Programa Fome Zero; Caderneta da Criança; Programa de Incentivo ao Aleitamento Materno; Programa de Combate à Diarréia e Norma Brasileira de Comercialização de Alimentos para Lactentes e Crianças de Primeira Infância e de Bicos, Chupetas e Mamadeiras NBCAL (Lei ${ }^{\circ}$ 11265). Das 10 políticas elaboradas a nível Estadual, foram encontradas sete delas em Santa Maria: Atendimento às Dificuldades Auditivas; Atenção à Saúde Ocular; Controle da Qualidade da Água Consumida nas Escolas Estaduais, Creches e Aldeias Indígenas; Controle Toxicológico dos Alimentos Consumidos em Escolas Estaduais, Creches e Aldeias Indígenas; Política Estadual de Triagem Neonatal; Programa Viva a Criança; Notificação Compulsória de Maus Tratos Contra Crianças e Adolescentes. Apenas oito programas de saúde foram elaborados para a atuação no ambiente escolar, sendo eles: Programa Veja Bem Brasil; Atendimento às Dificuldades Auditivas; Atenção à Saúde Ocular; Controle da Qualidade da Água Consumida nas Escolas Estaduais, Creches e Aldeias Indígenas; Controle Toxicológico dos Alimentos Consumidos em Escolas Estaduais, Creches e Aldeias Indígenas; Projeto Escola e Saúde; Programa Fome Zero Distribuição de Leite e Hortifrutigranjeiros e Programa de Capacitação de Educadores.

Até a década de 80 , as práticas de saúde vigentes no Brasil eram centradas na figura do médico, no biologicismo e no curativismo ${ }^{4}$. A partir do movimento da reforma sanitária, nos anos 80, começa a se delinear um novo projeto de saúde que passa a valorizá-la como direito de todo cidadão a ser garantido pelo Estado, envolvendo princípios como a eqüidade do atendimento, a integralidade da atenção e a participação social do usuário ${ }^{5}$. Essas mudanças proporcionaram condições para o Estado desenvolver uma série de políticas de saúde voltadas para os mais variados grupos populacionais1.

Nesse contexto, destaca-se a criança como um importante grupo populacional que merece atenção por parte do Estado. O momento atual favorece o entendimento mais amplo da situação da infância como estando associada a uma série de outras questões de ordem política, econômica e social, assim como a fatores estruturais e conjunturais que permitem a manutenção da fantástica desigualdade social, que ainda caracteriza este país ${ }^{6}$. Pesquisas recentes consolidam a imagem das crianças como o grupo prioritariamente desfavorecido de nossa sociedade ${ }^{7}$. O desnível no que se refere à cobertura de 
serviços públicos entre as estatísticas das crianças e todas faixas etárias da sociedade brasileira corresponde a: $55 \%$ contra $64 \%$ em água encanada, $78 \%$ contra $84 \%$ em esgoto e $66 \%$ contra $73 \%$ em coleta de lixo ${ }^{3}$.

Visto que a escola, além da função pedagógica, quando o aluno aprende a ler, escrever, calcular, etc, também tem a função social, a qual prepara o aluno para a vida, desenvolvendo nele a consciência de cidadania, meio ambiente, saúde, etc, é necessário que ela esteja integrada aos mais diversos setores da sociedade, principalmente o da saúde ${ }^{8}$. Além disso, a escola é o ambiente em que a criança passa a maior parte de seu tempo, por isso há que se pensar no estabelecimento de políticas básicas de saúde consistentes para esses locais, permitindo que todas as crianças tenham acesso a serviços de qualidade de forma integral, a fim de garantir a sua boa formação, tanto física quanto psicológica ${ }^{6}$.

Quando ocorre a integração entre saúde e educação, os serviços de saúde e as escolas atuam conjuntamente resultando em compartilhamento de conhecimentos, vivências e informações entre os profissionais das duas áreas ${ }^{9}$. Dessa maneira, toda a comunidade se beneficia, pois a escola passa a atuar como um centro de educação e saúde irradiador para os lares ${ }^{10}$.

\section{CONCLUSÃO}

A realização desse trabalho nos mostrou a importância da existência de políticas públicas de saúde voltadas para a criança implantadas no país, pois é através delas que a saúde infantil ganha um espaço na sociedade. Após o delineamento da pesquisa, pudemos observar que os programas de saúde existentes para a criança, apesar de serem numerosos, não atingem com eficácia o ambiente escolar, local em que ela está inserida na maior parte do tempo.

Os poucos programas de saúde inseridos na escola, como mostram os resultados, faz-no concluir que é reduzida a articulação entre os setores de educação e de saúde, o que, de certa forma, prejudica a promoção de saúde nesse meio. A integração entre esses setores da sociedade é fundamental uma vez que, seus profissionais atuando juntos e continuamente dentro da escola, fornecem subsídios para uma vida mais saudável da criança e da comunidade.

\section{REFER ÊNCIAS BIBLIOGRÁFICAS}

1. Silva EM, Nozawa MR, Silva JC, Carmona SAMLD. Práticas das enfermeiras e políticas de saúde pública em Campinas, São Paulo, Brasil. Cadernos de Saúde Pública 2001; julho-agosto; 17(4): 989-998;

2. Rossetti-Ferreira MC, Ramon F, Silva APS. Políticas de atendimento à criança pequena nos países em desenvolvimento. Cadernos de Pesquisa 2002; março; n. 115: 65-100;

3. Néri M, Costa Dr. O Tempo das Crianças. Revista Ensaios Econômicos da EPGE 2002; dezembro; n. 468;

4. Gomes FZ, Adorno RCF. Crescimento e desenvolvimento na prática dos serviços de saúde. Revisão histórica do conceito de criança. Revista de Saúde Pública 1990; março; 24(3): 204-211;

5. Casate JC, Corrêa AK. Humanização do atendimento em saúde: conhecimento veiculado na literatura brasileira de enfermagem. Revista Latino-americana de Enfermagem 2005; janeirofevereiro; 13(1): 105-111;

6. Rizzini I, Barker G, Cassaniga N. Políticas sociais em transformação: crianças e adolescentes na era dos direitos. Educar em Revista 1999;

7. Amorim KS, Yazlle C, Rossetti-Ferreira MC. Saúde e doença em ambientes coletivos de educação da criança de 0 a 6 anos. Reunião Anual da ANPEd, 1999. Disponível em http//: www.ced.ufsc.br . Acesso em 28 de setembro de 2007;

8. Miranda MIF. Em busca da definição de pautas atuais para o delineamento de estudos sobre a saúde da criança e do adolescente em idade escolar. Revista Latino-Americana de Enfermagem 2000; dezembro; 8(6): 83-90;

9. Rizzetti DA, Fabbrin APA, Trevisan CM. Prevenção de Distúrbios Neuropsicomotores e Estimulação Essencial em Crianças nas Creches Assistenciais do Município de Santa Maria. Anais da $21^{\text {a }}$ Jornada Acadêmica Integrada da Universidade Federal de Santa Maria 2006; novembro 28 - 30; Santa Maria, Rio Grande do Sul, Brasil;

10. Fernandes MH, Rocha VM, Souza DB. A concepção sobre saúde do escolar entre professores do ensino fundamental $\left(1^{\text {a }}\right.$ a $4^{a}$ séries). Revista História, Ciências e Saúde 2005; maio-agosto; 12(2): 283-291.

Endereço para correspondência:

Danize Aparecida Rizzetti

Endereço: RS 509, Faixa Velha de Camobi, km 06, n 4511, apto, 01, Camobi, Santa Maria - RS.

CEP 97110-620.

E-mail: danize_rizzetti@hotmail.com.

Fones: (55) 3226-2804 ou (55) 91345770. 